The Feeding of Pre-School Children (Survey of a World Problem). By F. Le Gros Clark. (Pp. 51. 1s. 6d.) London: National Society of Children's Nurseries. 1951.

The main thesis of this booklet is that preached so often in the last 20 years by Dr. C. D. Williams, of the Colonial Service and of the World Health Organization, namely the crying need throughout so much of the world for better feeding of children between the ages of 12 months and 3 or 4 years of age. The author begins with a consideration of mortality rates among young children in different countries; he contrasts the mortality per 1,000 living in the age group $1-4$ years in New Zealand $(1 \cdot 7)$ or Sweden $(2 \cdot 2)$ with that of Mexico $(48 \cdot 2)$ or Egypt (78.9), and compares these again with the much lower mortalities between 5 and 9 years of age (e.g. Mexico
7.9 and Egypt 7.6). He stresses the need for a better diet from the time of weaning as probably the major factor in lowering mortality in this age group, and shows how in many parts of the tropics, the Far East and in Latin America this is bound up with the provision of milk substitute and with the education of parents. Apart from the possibility of increased milk production, the author urges the wide use of skimmed dried milk with cereal and bean products, reinforced with calcium, iron and vitamins $A$ and $D$, as a weaning diet. It is a pity, for the thread of the author's argument is interrupted by an irrelevant chapter mainly concerned with the provision of day nursery and nursery schools in different countries. May this booklet rouse the conscience of some among us who can help towards the better feeding of children in British colonies.

\title{
FILM REVIEWS
}

The Development of Manipubation. $16 \mathrm{~mm}$., silent, monochrome, 20 minutes.

This new film made by Professor Illingworth is, like his film, 'The Development of Locomotion' based on Gesell's work. It shows what children can do with their hands at different ages. It is a very useful survey and should be found valuable for teaching.

Surpise Attack. $16 \mathrm{~mm}$., sound, black and white, 10 minutes. Made by the Central Office of Information and Central Council for Health Education for the Ministry of Health. 1951. Distributed free by the Central Film Library.

This is a dramatic appeal to parents to have their children vaccinated in infancy. The public may draw the conclusion that mass vaccination is advocated but this is a small point. A reviewer must have his fun, and yours would criticize the medical officer of health for touching the face of a smallpox patient and then putting his hand in his pocket. The film is well made and medical students as well as parents will profit from seeing it.
You Children's Play. $16 \mathrm{~mm}$., sound, 20 minutes.

You Children Walling $16 \mathrm{~mm}$., sound, 20 minutes. Made by the Central Office of Information in collaboration with the Central Council for Health Education for the Ministry of Health. 1951. Available from the Central Film Library.

These films are designed for showing in infant welfare centres and to parents' clubs and nursery school staffs.

Your Children's Play conveys a very good attitude towards play and toys. One hesitates a little before recommending it because it shows 'stupid' parents without conveying that they are more over-anxious, over-worked or uninformed, than essentially stupid. Despite this fault the film will be a very useful one.

Your Children Walking could have given more explanation in the way muscles and tendons act in the legs and feet and less time in telling parents to urge their children to adopt a good posture. The remaining advice is very good and the film will be useful for nurses as well as for parents. 